\title{
CONCEPÇÕES \\ DE ANÁLISE LINGUÍSTICA NA \\ FORMAÇÃO \\ INICIAL DE PROFESSOR \\ DE LÍNGUA \\ PORTUGUESA
}

\section{CONCEPCIONES DE ANÁLISIS LINGÜÍSTICO EN LA FORMACIÓN INICIAL COMO PROFESOR DE LENGUA PORTUGUESA}

\author{
CONCEPTIONS OF LINGUISTIC ANALYSIS IN THE INITIAL EDUCATION OF PORTUGUESE \\ TEACHERS
}

Maria de Lourdes Rossi Remenche*

Nívea Rohling**

Universidade Tecnológica Federal do Paraná

\begin{abstract}
RESUMO: Este artigo tematiza as concepções de prática de análise linguística, materializadas em atividades elaboradas por licenciandos de um curso de Letras Português-Inglês em uma universidade pública no sul do Brasil. Os enunciados analisados constituem-se de 08 (oito) conjuntos de atividades de análise linguística, elaborados por ocasião de escrita de projeto de Estágio Supervisionado de Língua Portuguesa. A fundamentação teórico-metodológica embasou-se nos estudos teóricos que iniciaram a reflexão sobre análise linguística e ensino no Brasil na década de 1980 (GERALDI, 1984; 1997; FRANCHI, 1991), bem como se orientou pelas recentes pesquisas na área (MENDONÇA, 2006; REINALDO; BEZERRA, 2013). A análise evidenciou uma concepção de análise linguística que preconiza a linguagem em uso e uma perspectiva mais reflexiva da língua. No entanto, o discurso da tradição em ensino de língua portuguesa mostrou-se saliente em algumas atividades elaboradas pelos licenciandos. Dessa forma, o estudo aponta não só um movimento de prospecção, mas também de retroação, visto que é possível constatar um
\end{abstract}

\footnotetext{
* Professora Adjunta do Departamento Acadêmico de Linguagem e Comunicação (DALIC) da Universidade Tecnológica Federal do Paraná (UTFPR/Câmpus Curitiba). Doutora em Linguística pela Universidade de São Paulo/USP. E-mail: mremenche@utfpr.edu.br.

** Professora Adjunta do Departamento Acadêmico de Linguagem e Comunicação (DALIC) da Universidade Tecnológica Federal do Paraná (UTFPR/Câmpus Curitiba). Docente do Programa de Pós-Graduaço em Estudos de Linguagens (PPGEL). Doutoraem Linguística pela UniversidadeFederaldeSantaCatarina. E-mail:niveajoi@yahoo.com.br.
} 
processo de assimilação das novas demandas de ensino da língua na escola, e, ao mesmo tempo, se faz presente a reprodução de modelos e práticas gramaticais tradicionais.

PALAVRAS-CHAVE: formação inicial de professor; análise linguística; concepções de ensino-aprendizagem de língua materna.

RESUMEN: Este artículo analiza las concepciones de práctica de análisis lingüístico, materializadas en actividades que elaboraron los licenciandos de un curso de Letras Portugués-Inglés en una universidad pública en el sur del país. Los enunciados se constituyen de 08 (ocho) conjuntos de actividades de análisis lingüístico, hechos a partir de la redacción de proyecto de Práctica Supervisada de Lengua Portuguesa. La fundamentación teórico-metodológica se basó en los estudios teóricos que iniciaron la reflexión sobre análisis lingüístico y enseñanza en Brasil en la década de 1980 (GERALDI, 1984, 1997; FRANCHI, 1991), así como se ha orientado por las recientes investigaciones en el área (MENDONCA, 2006; REINALDO; BEZERRA, 2013). El análisis ha evidenciado una concepción de análisis lingüísitico que preconiza el lenguaje en uso y una perspectiva más reflexiva de la lengua. Sin embargo, el discurso de la tradición en enseñanza de lengua portuguesa se ha evidenciado en algunas actividades que los licenciandos elaboraron. Así, el estudio apunta no solo un movimiento de prospección, sino de retroacción, visto que es posible constatar un proceso de asimilación de las nuevas demandas de enseñaza de la lengua en la escuela, aunque esté presente, todavía, la reprodución de modelos y prácticas gramaticales tradicionales.

PALABRAS CLAVE: formación inicial como profesor; análisis lingüístico; concepciones de enseñanza-aprendizaje de lengua materna.

ABSTRACT: This article addresses the conceptions of teaching and learning linguistic aspects present in activities of linguistic analysis elaborated by undergraduate students of a course in Languages (Portuguese and English) of a public university in the south of the Brazil. The rubrics herein analyzed are composed by 8 (eight) sets of activities of linguistic analysis, which were created by the students for the discipline of Supervised Practice on Portuguese Language Teaching. Our theoretical and methodological framework is based on the theoretical studies that initiated the reflection on linguistic analysis and language teaching in Brazil during the 80s (GERALDI, 1984, 1997; FRANCHI, 1991), as well as on recent researches in the area (MENDONÇA, 2006; REINALDO; BEZERRA, 2013). On the one hand, the analysis showed a conception of linguistic analysis that emphasizes language in use and a more reflective perspective of language. On the other hand, it showed that the traditional discourse of Portuguese language teaching was salient in some activities. Thus, the analysis points out not only towards advancements, but also towards retrospection, once it is possible to notice a process of assimilation of new demands on language teaching at school, but, at the same time, the reproduction of traditional grammatical patterns and practices.

KEYWORDS: initial teacher education; linguistic analysis; conceptions of language teaching and learning.

\section{INTRODUÇÃO ${ }^{1}$}

$\mathrm{Na}$ esfera escolar, tradicionalmente, ensinar português é sinônimo de ensinar gramática. Entretanto, o ensino de língua portuguesa na escola vem, desde a década de 1980, sofrendo acentuadas mudanças no que diz respeito aos objetivos e conteúdos de ensinoaprendizagem da disciplina. Nessa mesma década, os estudos linguísticos já sinalizavam novos direcionamentos para os processos de ensino-aprendizagem de língua materna, sobretudo, ao ensino de gramática, que passou a ser ressignificado sob a perspectiva do trabalho com a análise linguística (doravante AL). Não se trata apenas, como salienta Geraldi (1984), de uma mudança terminológica, mas antes de tudo de uma nova forma de compreender o trabalho com a língua em sala de aula, tendo como base uma noção de língua como atividade e como interação entre sujeitos culturalmente situados. ${ }^{1}$ Este texto é resultado das ações de pesquisa do Grupo de Pesquisa em Linguística Aplicada - GRUPLA - da Universidade Tecnológica Federal do
Paraná/Câmpus Curitiba. 
Embora, como dito antes, as pesquisas acadêmicas apontem tais mudanças no ensino de LP há cerca de 30 anos $^{2}$, sabemos que elas não são assimiladas ${ }^{3}$ no espaço escolar de modo tão rápido e de forma especular, tendo em vista tratar-se de discursos que permeiam a pesquisa acadêmica em intersecção com a prática docente na escola. Nesse contexto, o professor, que é o sujeito que delimita/agencia os conteúdos de ensino e aprendizagem em sala de aula, orienta sua prática docente a partir de diversos discursos: o da formação inicial e continuada; o dos autores de livro didático; o dos documentos oficiais de ensino e das políticas públicas para educação. Sobre essa questão, retomamos Tardif (2002, p. 262-269), ao ponderar que os saberes profissionais de professor são variados e heterogêneos. Esses saberes incluem: a cultura pessoal, assentada na sua história de vida e de sua cultura escolar anterior (ele se apoia também em certos saberes disciplinares advindos da universidade); os conhecimentos didáticos oriundos da formação continuada; os conhecimentos veiculados pelos programas, guias e manuais escolares; seu próprio saber, ligado à experiência de trabalho na relação com seus pares de profissão.

Assim, é possível refletir que, apesar de toda a empreitada de pesquisa e formação de professor no que diz respeito ao trabalho com a língua de forma situada e reflexiva, hoje, no trabalho docente, a articulação entre a leitura, a produção textual e a análise linguística ainda é um desafio. Segundo Reinaldo e Bezerra (2013, p. 33), a prática de AL foi instituída pelos documentos oficiais como um dos eixos norteadores do ensino de língua portuguesa, entretanto, não tem sido abordado na mesma proporção em que o são os demais eixos (leitura e escrita). Nessa mesma perspectiva, Rodrigues (2014, p.78) evidencia a complexidade desse objeto de ensinoaprendizagem $[\mathrm{AL}]$, tendo em vista que, na sua elaboração didática, o professor precisa agenciar diferentes conhecimentos: conhecimento teórico sobre os estudos linguísticos; a prática social de uso da língua, isso porque os fatos da língua se materializam nos gêneros discursivos; os conhecimentos especializados para modalizar o conhecimento científico; e o uso social, de modo que possa ser trabalhado na escola.

A AL, nesse contexto teórico-aplicado, constitui-se em um aspecto importante a ser abordado tanto na formação inicial como na formação continuada de professor de LP.

Diante dessa problematização, este artigo apresenta uma análise de atividades de AL, elaboradas por licenciandos em um curso de Letras-Português-Inglês de uma universidade pública do sul do Brasil, a fim de refletir sobre as concepções de prática de AL na formação inicial.

Para tanto, tomamos como base epistêmica a concepção dialógica de linguagem (BAKHTIN, 2003; BAKHTIN; VOLOCHÍNOV, 2004) e a noção de AL ancorada nos estudos da linguagem (GERALDI, 1984, 1997; MENDONÇA, 2006; REINALDO; BEZERRA, 2013). Inicialmente, delineamos o quadro teórico a partir da noção de AL desenvolvidas nos estudos da linguagem. Em seguida, apresentamos as regularidades encontradas no processo de análise dos dados.

\section{PRÁTICAS DE LINGUAGEM EM SALA DE AULA: DA GRAMÁTICA À ANÁLISE LINGUÍSTICA}

O processo de ensino-aprendizagem de LP esteve centrado, durante longo período, em um ensino prescritivo de regras gramaticais, de forma descontextualizada e desvinculada dos usos reais da língua escrita e falada e do processo de leitura e de escrita.

Vale destacar que essa realidade está, pois, enraizada em questões históricas, considerando que a força do discurso da tradição do ensino de Língua Portuguesa se ancora na primazia dos estudos gramaticais - de cunho prescritivo e conceitual - no ensino de língua durante o século XIX e grande parte do século XX. Nesse período, o ensino pautou-se em uma perspectiva de gramática conceitual, baseada em uma única modalidade da língua portuguesa, conforme descreve Soares (2002). Nesse sentido, Faraco (2008, p. 185) argumenta que "[...] tradicionalmente, sempre se identificou, no Brasil, o ensino de português com o ensino da gramática”. Por

\footnotetext{
${ }^{2}$ O livro “O texto na sala de aula”, organizado em 1984 por João Wanderley Geraldi, é considerado um marco nessa perspectiva teórica.

3‘Assimilação' neste texto é compreendida tal como propõem Morson e Emerson (2008, p. 235), sendo um termo geral para designar os processos mediante os quais o discurso dos outros vem a desempenhar um papel no nosso próprio discurso interior. Nesse sentido, assimilação implica acentuar a palavra.
} 
muito tempo a concepção de conteúdo de ensino e aprendizagem na disciplina escolar de LP ancorou-se em uma perspectiva gramatical, sobretudo, em uma gramática prescritiva e conceitual centrada fortemente em uma abordagem metalinguística.

Esse modo de conceber o ensino-aprendizagem de língua na escola foi problematizado no âmbito das pesquisas científicas (BRITTO, 1997; GERALDI, 1984, 1997; SOARES, 2002) e motivou a reflexão e a busca por abordagens mais significativas para as diferentes realidades culturais e os sujeitos envolvidos nesse processo. Nessa perspectiva, a proposição de práticas pedagógicas com base na concepção de AL tem por objetivo possibilitar um ensino-aprendizagem de língua que articule a reflexão da língua às demais práticas linguageiras (fala, escuta, leitura e escrita).

Nesse contexto, o termo Análise Linguística, cunhado por Geraldi (1984), constituiu-se a partir de uma concepção reflexiva sobre o sistema linguístico e sobre os usos da língua, visando ao tratamento escolar de fenômenos discursivos, textuais e gramaticais. Para isso, Geraldi, na década de 1980, propôs uma reorientação para o ensino de LP a partir de uma abordagem da leitura e da escrita de textos como práticas processuais significativas socialmente e integradas, e da análise dos problemas observados na produção textual dos alunos, que são tomados como ponto de partida para a prática de AL. Contudo, ressaltamos que, na época da publicação do texto "Unidades básicas do ensino de português" (1984), ainda não se estava discutindo a teoria de gêneros discursivos na esfera escolar; por isso, o texto está centrado nas tipologias/taxionomias escolares, pois era o conhecimento que se tinha na época. Contemporaneamente, os textos curtos, nas aulas de leitura, não são mais considerados tão somente como elementos para a alimentação temática das aulas de produção textual. Na prática de leitura, articula-se a prática de AL e não somente a partir da produção dos alunos.

Tal abordagem implica refletir sobre a estrutura da língua bem como sobre seu funcionamento no interior das práticas sociodiscursivas, contribuindo para a ampliação do domínio de atividades de fala, escuta, leitura e escrita. Na mesma linha, Reinaldo e Bezerra (20013, p. 16) concebem a AL como reflexão sobre recursos linguístico-textual-enunciativos, tanto em relação à compreensão e à produção de textos orais e escritos, quanto em relação à descrição do sistema da língua. Para Mendonça (2006), a AL possibilita a reflexão consciente sobre fenômenos gramaticais e textual-discursivos que atravessam os usos linguísticos, tanto em situações de leitura/escuta quanto em produções de texto ou reflexões sobre os usos da língua.

Apesar dessa ampliação conceitual, o trabalho com AL não exclui a gramática de sala de aula, visto que não há usos linguísticos ou mesmo reflexão sobre a língua sem que se lance mão de uma gramática. Nessa perspectiva Geraldi (1997, p.74) esclarece que

O uso da expressão 'análise linguística' não se deve ao mero gosto por novas terminologias. A análise linguística inclui tanto o trabalho sobre as questões tradicionais da gramática quanto questões amplas a propósito do texto, entre as quais vale a pena citar: coesão e coerência internas do texto; adequação do texto aos objetivos pretendidos; análise dos recursos expressivos utilizados [...]; organização e inclusão de informações etc.

Mendonça (2006) argumenta que a AL abrange, entre vários aspectos, os estudos gramaticais, porém em um paradigma diferente, visto que os objetivos pretendidos são outros. Desse modo, a AL envolve não só princípios e fundamentos do funcionamento da língua, mas também contribui para a sistematização de descobertas sobre os usos reais da língua.

No entanto, no contexto escolar, para que essa perspectiva se efetive faz-se necessário realizar atividades que possibilitem essa reflexão de modo a integrar atividades de linguagem e o pensar sobre elas, ou seja, refletir sobre elementos e fenômenos linguísticos e sobre estratégias discursivas, com foco na produção de sentido e nos usos da língua. Por tudo isso, a AL é parte das práticas de letramento escolar, consistindo numa reflexão explícita e sistemática sobre a constituição e o funcionamento da linguagem nas dimensões sistêmica, textual, discursiva e também normativa, com o objetivo de contribuir para o desenvolvimento de habilidades de leitura/escuta, de produção de textos orais e escritos e de análise e sistematização dos fenômenos linguísticos (MENDONÇA, 2006).

Nessa concepção, as práticas e atividades desenvolvidas em sala de aula precisam explorar a reflexão voltada para a produção de sentidos e/ou para a compreensão mais ampla dos usos e do sistema linguístico, a fim de contribuir para a formação de sujeitos 
leitores-produtores de gêneros diversos, aptos a participarem dos mais variados eventos de letramento ${ }^{4}$ de forma cidadã e crítica. Em outras palavras, a AL se constitui em instrumental potencializador para as práticas de leitura e de produção de texto (escrita e oral), visto que contribui para a análise do funcionamento da língua e do uso das diversas variantes linguísticas que circulam socialmente.

Para que isso ocorra, no entanto, as atividades propostas na disciplina precisam ir além da exploração de aspectos de metalinguagem, explorando saberes linguísticos vinculados ao uso da linguagem e leitura/produção dos gêneros discursivos. Nesse sentido, os PCN de Língua Portuguesa (1998) já privilegiaram a dimensão interacional e discursiva da língua, estabelecendo que os conteúdos da área precisam se articular em torno de dois grandes eixos: o uso da língua oral e escrita e a reflexão acerca desses usos.

Ainda que a reflexão seja constitutiva da atividade discursiva, no espaço escolar reveste-se de maior importância, pois é na prática de reflexão sobre a língua e a linguagem que pode se dar a construção de instrumentos que permitirão ao sujeito o desenvolvimento da competência discursiva para falar, escutar, ler e escrever nas diversas situações de interação. (BRASIL, 1998, p. 34)

Para fazer esse trabalho articulado entre as práticas linguageiras, o professor precisa lançar mão de uma série de atividades recursivas e interdependentes a fim de desenvolver as capacidades meta e epilinguística. Geraldi (2002, p.63) argumenta que

Todas essas considerações mostram a necessidade de transformar a sala de aula em um tempo de reflexão sobre o já-conhecido para aprender o desconhecido e produzir o novo. É por isso que atividades de reflexão sobre a linguagem (atividades epilinguísticas) são mais fundamentais do que aplicação a fenômenos sequer compreendidos de uma metalinguagem de análise construída pela reflexão de outros. Aquele que aprendeu a refletir sobre a linguagem é capaz de compreender uma gramática - que nada mais é do que o resultado de uma (longa) reflexão sobre a língua; aquele que nunca refletiu sobre a linguagem pode decorar uma gramática, mas jamais compreenderá seu sentido.

Nessa mesma linha, Travaglia (2001, p.34) pontua que

As atividades epilinguísticas são aquelas que suspendem o desenvolvimento do tópico discursivo (ou do tema ou do assunto), para, no curso da interação comunicativa, tratar dos próprios recursos linguísticos que estão sendo utilizados, ou de aspectos da interação. [...] A atividade epilinguística pode ser ou não consciente. Se pensamos que inconsciente se relaciona com a gramática de uso, se consciente parece se aproximar mais da gramática reflexiva, todavia, de qualquer forma há uma reflexão sobre os elementos da língua e de seu uso relacionada ao processo de interação comunicativa.

Partindo da experiência concreta de leitura e de produção de textos orais e escritos, o trabalho com a AL exige, portanto, por parte dos licenciandos/professores, uma postura reflexiva, que se dá não só no diálogo entre as possibilidades de interpretação de um texto e as marcas gramaticais de organização, coesão e coerência, mas também relacione-se às escolhas nos vários níveis. É um trabalho que contribui para que os estudantes se apropriem não só de conhecimentos declarativos e conceituais, como também de procedimentos e de saberes emancipatórios para que possam interagir em diferentes situações sociais.

Franchi (1991, p.20), nessa perspectiva, argumenta que

Interessa pouco descobrir a melhor definição de substantivo ou de sujeito ou do que quer que seja. [...] Mas interessa, e muito, levar os alunos a operar sobre a própria linguagem, rever e transformar seus textos, perceber nesse trabalho a riqueza das formas linguísticas disponíveis para suas mais diversas opções.

Assim, podemos dizer que a proposição de atividades de ensino-aprendizagem a partir de uma abordagem epilinguística favorece a reflexão sobre a língua, de modo que os estudantes possam qualificar a leitura e a produção de seus textos.

\footnotetext{
${ }^{4}$ Nesse texto, um evento de letramento é entendido tal como definido por Heath (1982, p. 93): “[...] qualquer situação em que um fragmento de escrita integra a natureza das interações dos participantes e seus processos interpretativos".
} 
A relação entre AL e produção de textos no ensino-aprendizagem de língua também foi discutida por Bakhtin, na década de 1940, na Rússia. Em recente publicação, no Brasil ${ }^{5}$, mais precisamente no artigo intitulado "Questões de estilística no ensino da língua", Bakhtin propõe uma sistematização para o trabalho com AL em uma turma de $7^{a}$ série. Nesse texto, Bakhtin se mostra um professor atento aos aspectos do ensino de língua, tendo em vista que propõe um conjunto de atividades articuladas centrado na análise estilística de um uso linguístico particular (o período composto por subordinação).

O objetivo de Bakhtin era explicar melhor o papel da estilística nas aulas de língua, uma vez que "as formas gramaticais não podem ser estudadas sem que se leve em conta seu significado estilístico. Quando isolada dos aspectos semânticos e estilísticos da língua, a gramática inevitavelmente degenera em escolasticismo" (BAKHTIN, 2013, p. 23). Esse caminho metodológico apresentado pelo autor - estudo da estilística - seria o que chamamos hoje de análise epilinguística, que focaliza os usos linguísticos bem como uma reflexão sobre as escolhas linguísticas dos falantes com enfoque na produção de sentidos.

A partir de análise de textos produzidos por seus alunos, Bakhtin (2013, p.29, grifo do autor) verificou que esses estudantes conheciam as regras sobre o uso do período sem conjunções em textos alheios, mas "[...] não sabiam em absoluto utilizar essa forma em seus próprios textos, não sabiam utilizá-la de modo criativo. Isso aconteceu porque o significado estilístico dessa forma maravilhosa não foi devidamente abordado na $7^{\text {a }}$ série.”.

A partir de reflexões sobre a própria prática docente, Bakhtin mostra que os fatos da língua são ensináveis de forma organizada e sistematizada. Como dito antes, o fenômeno abordado por Bakhtin em sua turma era o caso da subordinação com conjunção. $\mathrm{O}$ autor usa o seguinte exemplo retirado de um texto literário (Puchkin): 1. Triste estou: o amigo comigo não está.; 2. Triste estou, porque o meu amigo não está comigo.

No espaço-tempo da aula, a fim de tratar do uso estilístico da conjunção e a perda da expressividade que tal uso produz no enunciado, Bakhtin (2003) articulou o processo de ensino-aprendizagem a partir de ações sistematizadas que buscaram: 1. Mostrar o período em estudo (sem conjunção), transformando-o em período composto com a conjunção 'porque'; 2. Questionar os alunos acerca da diferença estilística entre as duas orações; 3 . Analisar a gradual perda de expressividade na frase alterada; 4 . Analisar a influência da mudança em todo o contexto - como a ordem das palavras influenciam os sentidos; 5 . Levar os alunos a construírem suas próprias conclusões a partir da análise. (BAKHTIN, 2013).

Após essa análise mais refinada e sistemática junto aos estudantes, Bakhtin relata que o uso da composição sintática dos alunos melhorou significativamente em suas produções escritas. De acordo com Bakhtin (2013, p.40), "[...] essas análises explicam a gramática para os alunos; ao serem iluminadas pelo seu significado estilístico, as formas secas gramaticais adquirem novo sentido para os alunos, tornam-se mais compreensíveis e interessantes para eles". Para tanto, Bakhtin salienta que tal mudança da produção escrita dos alunos se deu pela aproximação com o "[...] discurso oral, vivo e expressivo, isto é, da linguagem da vida viva." (BAKHTIN, 2013, p. 42). Ou seja, por meio do trabalho com textos reais que circulam na sociedade.

Nessa perspectiva, é possível afirmar que a prática de AL potencializa a ampliação do repertório linguístico, o processo de leitura e produção de textos orais e escritos e, consequentemente, o processo de interação social. No interior das práticas de leitura e produção de textos, a AL promove a reflexão acerca dos sentidos possíveis, construções variadas ou até mesmo lacunas de natureza diversificada, podendo enfocar questões de ordem ortográfica, lexical, semântica, morfossintática, textual, discursiva. Esse pensar visa à compreensão do funcionamento interno da língua e precisa caminhar de uma percepção intuitiva dos fatos a uma progressiva reflexão consciente e sistematização, acompanhada da introdução do vocabulário gramatical básico de modo a desenvolver uma atitude intencional de observar e descrever a organização da língua. Nessa dinâmica, esses sujeitos mobilizam estratégias de leitura e de escrita ao mesmo tempo em que refletem sobre questões relacionadas à análise da língua em um movimento de interdependência, não dicotomizando a reflexão sobre os conhecimentos linguísticos e os seus usos, pois refletir sobre os usos da linguagem implica refletir sobre os conhecimentos linguísticos com os quais interagimos nas diferentes situações sociais.

${ }^{5} \mathrm{O}$ artigo foi traduzido recentemente do russo para o português por Sheila Grillo e Ekaterina V. Américo. 
Além do olhar atento para o progresso no aluno com vistas ao entendimento do fenômeno linguístico em pauta, Bakhtin discute a importância da mediação do professor nesse processo quando afirma que a ele [o professor] cabe "[...] ajudar neste processo de nascimento da individualidade linguística do aluno por meio de uma orientação flexível e cuidadosa." (BAKHTIN, 2013, p. 43). Para que tal posicionamento se concretize é preciso que essa perspectiva de trabalho com a AL seja colocada no centro das discussões na formação do professor de LP.

A seguir, apresentamos o encaminhamento metodológico da análise a ser relatada que, de certo modo, evidencia a prática da instância formadora, a saber, a universidade.

\section{PERCURSO METODOLÓGICO}

Para contextualizarmos o trabalho desenvolvido na formação de professores de LP faremos uma breve descrição do caminho percorrido por esses licenciandos em sua formação inicial.

No $5^{\circ}$ período do curso de Letras ${ }^{6}$, os licenciandos cursam simultaneamente as disciplinas de Metodologia do Ensino de Língua Portuguesa e Estágio Curricular I. O objetivo do trabalho conjunto com as duas disciplinas é colocar em diálogo as concepções de linguagem, letramento, processo de ensino-aprendizagem de leitura e produção de texto, considerando o trabalho com a reescrita de textos e AL a partir da produção de textos dos alunos. Tais conceitos são introduzidos na disciplina de Metodologia de Ensino, observando as orientações das políticas públicas dos documentos oficiais. Concomitantemente às discussões epistemológicas, ocorre a construção de um projeto didático a ser desenvolvido nas aulas de regências, ${ }^{7}$ realizadas na disciplina de Estágio Supervisionado.

O projeto de estágio consiste num documento em que os licenciandos planejam uma elaboração didática ${ }^{8}$ de suas aulas de regência a partir de um tema proposto pelo professor formador, mais especificamente o professor regente da turma em que a aula de regência será ministrada. A AL ocorre em dois momentos: por meio dos textos propostos para a leitura na fase inicial e a partir das produções escritas dos alunos na fase final do projeto. Assim, são elaboradas atividades focais de AL, que são objetos de análise neste texto.

Embora haja um embasamento teórico ${ }^{9}$, os licenciandos encontram grande dificuldade em materializar a elaboração didática dos conteúdos de ensino-aprendizagem, tendo em vista que precisam elaborar atividades de AL a partir de textos selecionados para o trabalho de determinado gênero discursivo. O que significa dizer que é exigido dos licenciandos um desempenho autoral, uma vez que precisam identificar as regularidades linguísticas dos textos-enunciados selecionados para o trabalho em sala de aula e utilizálas como mote para as atividades.

Mediante as dificuldades encontradas, observamos uma recorrência, por parte dos licenciandos, em retomar práticas de ensino tradicionais de gramática com foco em metalinguagem. Esse cenário suscitou uma investigação que gerou a presente análise.

Assim, foram selecionados para análise 08 (oito) conjuntos de atividades de AL, elaboradas pelos estudantes do $5^{\circ}$. Período de Letras $(2014 / 1)$ no interior do processo interacional aqui descrito. Tais textos são tomados como enunciados concretos tal como concebido

\footnotetext{
${ }^{6} \mathrm{O}$ Curso de Licenciatura Letras Português-Inglês em estudo se constitui de 08 semestres, totalizando um período de 04 anos.

${ }^{7}$ Os licenciandos observam 08 aulas em uma turma do Ensino Fundamental anos finais ou Ensino Médio e, em dupla, desenvolvem um plano para a regência de 04 aulas em que se agenciam atividades articuladas de leitura, produção de texto (oral e escrito) e AL.

${ }^{8}$ Segundo Rodrigues (2009), a concepção de elaboração didática se refere a uma didática praxiológica em que a construção do conhecimento é vista como processo e é resultado da opção por uma metodologia que considera a participação do professor e do aluno no processo didático.

${ }^{9}$ Foram discutidos na disciplina de Metodologia de Ensino de Língua Portuguesa textos teóricos sobre AL, a saber: Geraldi (1984, 1997); Mendonça (2006). Na disciplina de Estágio Supervisionado são estudados os documentos oficiais de ensino (PCNs e Diretrizes Curriculares da Educação Básica de Língua Portuguesa do Estado do Paraná) com enfoque na concepção de língua, objetos e finalidade do ensino-aprendizagem de Língua Portuguesa. Além disso, nesta fase do curso, os licenciados já cursaram disciplinas em que são abordadas as especificidades do trabalho com o texto em sala de aula e as práticas de linguagem como, por exemplo, Linguística Aplicada e Linguística Textual.
} 
na elaboração epistemológica do Círculo de Bakhtin. Buscamos identificar as regularidades e as singularidades nas atividades elaboradas, a fim de problematizar como a AL é ressignificada na elaboração didática construída por esses sujeitos em processo de formação principiante. A seguir, apresentamos os resultados da análise empreendida.

\section{O QUE DESVELAM AS ATIVIDADES DE ELABORADAS NA FORMAÇÃO INICIAL?}

Como dito antes, no desenvolvimento da disciplina de Estágio Obrigatório de Língua Portuguesa I, em diálogo com a disciplina de Metodologia de Ensino, apresentamos aos licenciandos a proposição de se trabalhar a AL articulada aos demais eixos de ensino de língua materna (leitura e produção de texto) por meio de uma elaboração didática.

Para tanto, houve uma orientação explícita nas referidas disciplinas de que o ponto de partida do trabalho com a linguagem em sala de aula fosse "[...] o gênero textual para chegarmos às unidades linguísticas, considerando a língua como ação entre os seus usuários (interação)" (REINALDO; BEZERRA, 2013, p. 64).

No entanto, não ocorre uma transposição direta dos conhecimentos mobilizados pela instância formadora (universidade) para atuação dos estagiários nas suas aulas de regência na disciplina de Estágio Obrigatório. Isso porque esses conhecimentos são "[...] afetados por novas condições históricas que os atualizam continuamente" (RIBEIRO, 2013, p. 272). Concordamos com a ponderação de Ribeiro (2013, p. 273) quando afirma que, na formação inicial, "[...] tanto os conhecimentos teóricos específicos da formação do professor de Português quanto à recriação destes no espaço da prática pedagógica se constituem orientados por forças históricas movidas pela complexidade e pela contradição que lhe são constitutivas”.

Tendo em vista essa complexidade e esse imbricamento de saberes diversos na formação inicial (saberes científicos e saberes oriundos da prática pedagógica), procuramos observar em que medida os saberes científicos da formação inicial, acerca das concepções de AL, mostram-se salientes nas atividades elaboradas pelos licenciandos. Ou seja, refletimos sobre os modos como as concepções epistemológicas no tocante ao trabalho com AL produziram ressonâncias nas atividades elaboradas, que seriam efetivadas nas aulas de regência.

Assim, como dito antes, na busca por compreender o modo como a AL foi elaborada didaticamente pelos licenciandos, analisamos um conjunto de atividades. Identificamos nesses enunciados diferentes movimentos dialógicos que apontam para uma intersecção de três tendências, discutidas por Reinaldo e Bezerra (2013) ao analisar atividades de AL em livros didáticos: a) tendência conservadora; b) tendência conciliadora; e c) tendência inovadora.

Segundo as autoras, a tendência conservadora enfatiza os conhecimentos propostos pela gramática tradicional em seus aspectos descritivos e prescritivos; já a tendência conciliadora, por seu turno, reflete influências teóricas oriundas da linguística e da tradição gramatical; e, por fim, a tendência inovadora assume denominações para o estudo da língua oriunda dos estudos linguísticos e se não apresenta uma sistematização no estudo relacionado à AL (REINALDO; BEZERRA, 2013).

No semestre 2013/2 foram desenvolvidas 08 (oito) atividades de AL, elaboradas pelos licenciandos, dentre os quais 06 foram elaboradas em dupla e 02 elaboradas individualmente. As atividades foram construídas a partir de textos de um determinado gênero discursivo, selecionados pelos licenciandos, propostos para prática de leitura nas aulas de regência.

A seguir, o quadro 01 apresenta uma descrição geral das atividades elaboradas: 


\begin{tabular}{|c|c|c|}
\hline Licenciandos & Gênero discursivo & Descrição geral das atividades \\
\hline Eliane e Marcelo ${ }^{10}$ & Relato Pessoal & Não houve elaboração de atividades focais de AL \\
\hline Fabiana e Carla & Charge & Não houve elaboração de atividades focais de AL \\
\hline Lucia e Manoela & Artigo Assinado & Não houve elaboração de atividades focais de AL \\
\hline Débora & Editorial & Não houve elaboração de atividades focais de AL \\
\hline Ana e Roberto & Carta Argumentativa & $\begin{array}{l}\text { Roteiro de leitura constituído de questões de interpretação de aspectos da } \\
\qquad \text { superfície do texto } \\
\text { Atividades constituídas de exercícios gramaticais }\end{array}$ \\
\hline Beatriz & Carta Argumentativa & $\begin{array}{l}\text { Atividades constituídas por exercícios focais de gramática e exercícios } \\
\text { epilinguísticos que focalizam a produção de sentido }\end{array}$ \\
\hline Camila e Fabiana & Artigo Assinado & $\begin{array}{l}\text { Atividades constituídas por exercícios focais de gramática e exercícios } \\
\text { epilinguísticos que focalizam a produção de sentido }\end{array}$ \\
\hline Giulia e Sara & Resumo & $\begin{array}{l}\text { Atividades constituídas por exercícios focais de gramática e exercícios } \\
\text { epilinguísticos que focalizam a produção de sentido }\end{array}$ \\
\hline
\end{tabular}

Quadro 01: Descrição geral das atividades

O quadro 01 evidencia que, dos 08 conjuntos de atividades, 04 não desenvolveram atividades mais focais de $\mathrm{AL}$. Ou seja, não elaboradas questões que explorassem fatos da língua mais específicos a partir da leitura de um texto do gênero em estudo. Embora tenha sido essa a orientação nas disciplinas de Estágio Obrigatório e Metodologia de Ensino de Língua Portuguesa, não entrou no horizonte apreciativo dos licenciandos o modo como se dá essa articulação entre leitura e AL no processo de elaboração didática. Em outras palavras, não houve uma assimilação acentuada dessa perspectiva teórico-metodológica sobre o trabalho com AL a ponto de ser "ignorada" por alguns licenciandos no desenvolvimento do projeto didático ${ }^{11}$. Nessas situações, as etapas que previam atividades focais de língua abarcavam somente questões de interpretação textual que focalizavam aspectos mais amplos de compreensão leitora.

Ainda conforme o quadro, Ana e Roberto elaboraram um conjunto de atividades que evidencia uma postura mais conservadora em relação à AL. Por fim, 03 conjuntos de atividades evidenciam uma maior assimilação das discussões teóricas realizadas nas disciplinas, tendo em vista a inserção de atividades que encaminhavam para um trabalho mais reflexivo sobre a língua.

A seguir, apresentamos a análise de 02 conjuntos de atividades de AL.

4.1 Análise de atividades de AL 01

\footnotetext{
${ }^{10}$ Os nomes apresentados são fictícios.

${ }^{11}$ Ao serem questionados sobre o motivo da ausência de atividades mais focais de AL no projeto, os sujeitos responderam que não souberam elaborá-las. Tal elaboração deveria se dar de modo autoral a partir de seleção e análise de textos do gênero em estudo, tendo como enfoque os sentidos produzidos na materialidade/estilo do texto. Podemos aventar que tal demanda proposta pela instância formadora se mostrou distante do horizonte dos sujeitos naquela etapa de sua formação profissional.
} 
No decorrer do projeto didático, os licenciandos elaboram atividades de AL em dois momentos: a) a partir dos textos propostos para leitura do gênero discursivo em estudo; b) a partir da análise das produções escritas dos estudantes. O conjunto de atividades de AL em tela refere-se ao que foi apresentado aos estudantes no momento pós-leitura do texto:

\section{Preencha as lacunas com os operadores argumentativos:}

Santíssimo Papa Bento XVI,

Assunto complexo é o que alude ao casamento envolvendo padres vinculados a essa Instituição, coordenada por Vossa Santidade, matéria bastante comentada, no Brasil, onde mais de 7 mil sacerdotes encontram-se em tal situação de matrimônio ou em união estável.

Sou sabedor de que a Santa Igreja apóia-se em dogmas milenares, construídos paulatinamente, os quais preceituam a dedicação exclusiva de seus servos, exigindo-lhes não manterem qualquer relacionamento conjugal. V.S. haveria de me afirmar que um padre não teria tempo para várias atribuições, o que considero equívoco, a geração corrente não deve ser comparada a civilizações antigas. Estamos na era em que as pessoas conseguem atender a vários chamados simultaneamente, sem, haver interferência entre um e outro e, sinceramente, não enxergo incompatibilidade entre exercer a função de um sacerdote e constituir família.

Não querendo contrariar as doutrinas que regem o Cristianismo, sugiro a Vossa Santidade analisar, junto aos conselhos que compõem o Vaticano, se não seria hora de rever alguns conceitos estabelecidos pelo Catolicismo, adequando-os ao nosso tempo. Em minha visão - repito - não existe qualquer empecilho para que essa mudança seja considerada. Sem querer comparar, a maioria das outras denominações religiosas permite que seus representantes possam conviver com uma mulher, ter filhos e, eles permanecem a serviço da Palavra de Deus, inclusive vivenciando na prática aquilo que ensinarão a seus fiéis.

É assim que me pronuncio, respeitando os preceitos que orientam a religião católica. Penso, Santo Padre, que o tema édeveras árduo, mas precisa ser discutido. Ao liberar o casamento para os sacerdotes da Igreja, o Vaticano poderia, , estar contribuindo para que alguns escândalos vivenciados pela Instituição fossem amenizados. Padres são seres comuns, de carne e osso, tenham o dom espiritual e retórico de nortear o bom caminho a seus seguidores. Precisam ter uma esposa, filhos, uma família própria, vivendo com consciência tranqüila e necessidades satisfeitas.

Com a sua bênção,

Catolicis Matrimonus.

\section{Substitua os termos em negrito por pronomes.}

“[... Como? A gente reunia a rapaziada, descíamos o morro e íamos juntos dar um rolezinho pelo shopping-o lugar preferido desses jovens da periferia de Porto Alegre. Esses jovens nos mostravam as marcas e lojas preferidas. Contavam como faziam de tudo para adquirir essas marcas (descrevemos todas as possibilidades em nossos papers). Havia um prazer e empoderamento nesse ato de descer até o shopping. Esses jovens não queriam assustar, porque nem imaginavam que a discriminação fosse tão grande que esses jovens pudessem assustar. Muito pelo contrário: esses jovens faziam um ritual de se vestir, de usar as melhores marcas e estar digno a transitar pelo shopping."

"[... A classe média disciplinada vê os jovens vestindo as marcas do mercado hegemônico para a qual a classe média serve. A classe média vê os sujeitos vestindo as mesmas marcas que a classe média veste (ou ainda mais caras), mas não se reconhece nos jovens cujos corpos parecem precisar ser domados. A classe média não se reconhece no Outro e sente um distúrbio profundo e perturbador por isso."

\section{Complete o seguinte trecho com os conectores abaixo, de modo a torná-lo coeso:}

além de - quando - embora - mas - se - que - que - como - mesmo que - se - como

A ansiedade costuma surgir se enfrenta uma situação desconhecida. Ela é benéfica prepara a mente para desafios, falar em público. provoca preocupação exagerada, tensão muscular, tremores, insônia, suor 
demasiado, taquicardia, medo de falar com estranhos ou de ser criticado em situações sociais, pode indicar uma ansiedade generalizada, requer acompanhamento médico, porque pode até gerar transtornos mais graves, fobia, pânico ou obsessão compulsiva. apenas 20\% das vítimas de ansiedade busquem ajuda médica, o problema pode e deve ser tratado. se procure um clínico-geral num primeiro momento, é importante a orientação de um psiquiatra, prescreverá a medicação adequada. A terapia, em geral, é à base de antidepressivos. "Hoje existe uma geração mais moderna desses remédios", explica o psiquiatra Márcio Bernik, de São Paulo, coordenador do Ambulatório de Ansiedade, da Faculdade de Medicina da Universidade de São Paulo. " mais eficazes, não provocam ganho de peso nem oscilação no

humor." Outra vantagem: não apresentam riscos ao paciente caso ele venha a ingerir uma dosagem muito alta.

Adaptado de:http://portaldoprofessor.mec.gov.br/fichaTecnicaAula.html?aula=36097

4. Complete o seguinte trecho utilizando conectores apropriados para estabelecer relações lógicas nas sentenças. (Obs: Os conectores não devem ser repetidos).

1 - Aspiramos o oxigênio

2 - Os invejosos morrerão,

3 - Mário chorava copiosamente,

4 - Não lamentemos o dia de hoje,

5 - O Peregrino marcha sempre, chova

6 - Penso, existo. rejeitamos o gás carbônico.

a inveja não morrerá nunca. sua esposa ria. o amanhã não vem. 8 faça sol.

Quadro 2: Atividades de AL 01

O primeiro conjunto analisado remete à tendência conservadora, conforme propõem Reinaldo e Bezerra (2013, p. 52), pois conserva a perspectiva da gramática tradicional na elaboração de atividades destinadas aos estudantes. A proposta de Ana e Roberto, no plano de aula, era a análise de fatores linguísticos que caracterizassem a tessitura textual por meio da exploração de regularidades discursivas, textuais e linguísticas de enunciados do gênero carta argumentativa. Para isso, foram propostos para leitura textos do gênero em questão, assim como foi apresentada uma lista de exercícios, compreendidos, pelos licenciandos, como sendo atividades de AL.

De modo geral, as atividades propostas são conservadoras, tendo em vista que logo na primeira atividade verifica-se que os comandos das questões remetem à cópia, identificação, tarefa de completar lacunas e retirada de informações da superfície do texto, ou seja, são atividades prescritivas que não exigem reflexão [atividade epilinguística] por parte dos estudantes.

A questão 01 se dá a partir de uma carta argumentativa, com temática distante da realidade do aluno e vocabulário relativamente complexo, evidenciando o uso de pronomes de tratamento. Além disso, não há informações acerca das condições de produção e circulação do texto. Na atividade, diferentemente de uma proposta reflexiva que parte do erro do próprio aluno para a autocorreção, o foco está no preenchimento de lacunas com operadores argumentativos. Embora se use uma nomenclatura oriunda dos estudos linguísticos [operadores argumentativos], mais especificamente da Linguística Textual, o comando segue uma linha conservadora que exige do aluno que complete as frases, desconsiderando o contexto estritamente textual. Não há nenhuma orientação sobre os recursos linguístico-expressivos que são mobilizados na carta para sustentar a argumentação. Dessa forma, embora o texto seja uma carta argumentativa, não se parte das regularidades de gênero para se chegar às unidades linguísticas.

Na segunda questão, o foco recai na coesão textual, para isso é solicitada a substituição de termos em destaque por pronomes. Verificamos novamente a perspectiva gramatical tradicional tanto na constituição do comando quanto na abordagem do tema e na elaboração da atividade. Os termos em destaque (esses jovens e a classe média) se repetem recorrentemente nos parágrafos e o estudante precisa apenas substitui-los pelos pronomes do caso reto (eles e ela). A atividade mobiliza conhecimentos básicos sobre pronome (apenas pronomes do caso reto) e coesão em uma prática de substituição que se repete. Há de se observar também que novamente não há nenhuma menção aos aspectos relacionados às regularidades de gênero e aos sentidos do texto. 
De modo semelhante, as questões 03 e 04 exploram o preenchimento de lacunas com conectores adequados ao contexto. Na questão 03, os conectores devem ser selecionados a partir de uma lista para o preenchimento de um texto informativo. Há a indicação de que esta questão foi adaptada de um planejamento didático disponível em um portal educativo, o que aponta a dificuldade de produzir, de modo autoral, as atividades solicitadas no processo formativo. De modo semelhante, na questão 04, o estudante deverá preencher as lacunas de frases descontextualizadas. Novamente, as atividades exploram competências mínimas de completar, identifica e preencher lacunas. Não há, no caso dos conectivos, uma indicação das particularidades semânticas das conjunções subordinativas, explicando que tais palavras auxiliares expressam relações puramente lógicas entre os períodos, são privadas e de elementos visual ou imagético (BAKHTIN, 2013, p. 32).

As atividades analisadas evidenciam a repetição de modelos conservadores de estudo de aspectos gramaticais, que não estabelecem uma articulação lógica entre as atividades propostas; ao contrário, se repetem de forma exaustiva, além de não suscitar uma reflexão sobre os usos, contextos e interlocutores das diferentes situações de comunicação em que esses sujeitos estão inseridos. A atividade puramente gramatical pouco faz avançar a aprendizagem dos alunos na apropriação dos usos da linguagem.

Em outras palavras, o ensino estritamente gramatical

[...] faz com que os estudantes somente aprendam, no melhor dos casos, a analisar frases prontas em um texto alheio [...], mas a linguagem escrita e oral dos alunos quase não se enriquece com as novas construções: eles não utilizam, de modo algum, muitas das formas gramaticais estudadas. (BAKHTIN, 2013, p. 28).

Em síntese, esse conjunto de atividades remete-nos à afirmação de Mendonça (2006, p. 223), quando problematiza a "[...] dificuldade [de professores] de articular a reflexão sobre os fenômenos linguísticos à produção de sentido, ao tratamento da norma e às necessidades de aprendizagem dos alunos".

4.2 Análise de atividades de AL 02

A seguir, apresentamos outro conjunto de atividades em que foi possível observar uma mescla entre as tendências conciliadora e inovadora, apontadas por Reinaldo e Bezerra (2013). A tendência conciliadora, segundo Reinaldo e Bezerra (2013), se mostra presente nos exercícios de vocabulário que contribuem para a compreensão do texto tanto global quanto de elementos da sua coerência interna. Já a tendência inovadora envolve a compreensão do conteúdo específico trabalhado e a capacidade de depreender regras a partir do estudo de tal conteúdo.

\section{ATIVIDADES DE ANÁLISE LINGUÍSTICA}

1) Os textos que acabamos de ler são artigos assinados, nos quais os autores buscam argumentar favorável ou desfavoravelmente sobre determinado assunto, além de obter a concordância do leitor. Nesse sentido, qual a posição defendida pelos autores dos artigos sobre o uso dos smartphones em sala de aula? Comprove com pelo menos uma passagem do texto.

2) Quais os argumentos utilizados pelos autores para demonstrar seus pontos de vistas? Comprove com passagens dos textos.

3) A autora do texto “A proibição do celular nas escolas faz sentido?” faz vários questionamentos no decorrer de seu texto. Qual é a função de tais questionamentos?

4) Rogério Tuma, autor do texto "Na sala de aula, não!" utiliza diversas vezes dados estatísticos para compor seu artigo, por quê?

5) Uma das marcas características de um texto coerente e coeso é a utilização do processo de referenciação, por meio de pronomes ou alguma outra palavra que remeta a algo que já foi dito no texto. Há, no primeiro artigo, uma sentença que explicita esse caso. Ela está reproduzida abaixo. Identifique as palavras que fazem referência a outras já citadas no texto e indique a que elas se referem. 
"Ao invés de coibir o uso do celular, as escolas deveriam incorporá-lo como um recurso que já tem uma forte ligação com a rotina dos estudantes. Se bem aplicados e com um planejamento bem elaborado, eles podem contribuir fortemente para envolver os alunos em um processo de aprendizagem baseado em projetos, envolvendo atividades desafiadoras e que são conectadas ao cotidiano do aluno. As escolas devem estimular a criação de conteúdos e o desenvolvimento de projetos educacionais e pedagógicos que o transformem em uma poderosa ferramenta de ensino e aprendizagem". 6) Algumas palavras - os conectivos - funcionam como ligação entre uma frase e outra, estabelecendo diferentes relações entre elas, como por exemplo, relação de oposição, demonstrada pelos conectivos mas, porém, todavia, contudo, no entanto etc. Na frase, "Mais de $90 \%$ deles, porém, são contra alguma regra que proíba celulares e afins nas salas de aula", o conectivo em negrito poderia ser substituído pelo conectivo da mesma família mas?

7) No texto de Tuma, retirado da Revista Carta Capital, há a expressão "engenhocas". À que ela se refere? Explique o porquê de o autor ter utilizado essa expressão.

8) No mesmo artigo, há entre parênteses uma adjetivação endereçada aos alunos. A que alunos especificamente essa locução adjetiva se refere? É depreciativo ou não? De que modo ela se relaciona com a posição defendida pelo autor ao longo do texto.

9) O trecho reproduzido abaixo possui uma recorrência do conectivo "com". Reescreva o trecho, de forma a não alterar o sentido, retirando um ou mais desses conectivos.

De acordo com recente pesquisa realizada pelo CEBRAP (Centro Brasileiro de Análise e Planejamento) com o apoio da Fundação Victor Civita com estudantes do Ensino Médio, com faixa etária entre 15 e 19 anos, residentes em São Paulo e Recife e renda familiar inferior a $R \$ 2,5$ mil, quase 60\% possuem um celular ou tablet com acesso à Internet e mais de um quarto deles já os utilizou para estudar e realizar atividades escolares.

Quadro 3: Atividades de AL 02

Camila e Fabiana organizaram suas atividades tendo como enfoque o gênero artigo assinado. Para tanto, trabalharam com dois textos do gênero sobre a temática o uso de smartphones em sala de aula. Os textos em discussão foram: "A proibição do celular nas escolas faz sentido?", de Luciana Allan (2013), especialista em tecnologia da educação; e o texto intitulado: "Na sala de aula, não", escrito pelo articulista da revista Carta Capital Rogério Tuma (2015).

A questão 01 aborda um nível mais amplo de análise, a saber, o gênero discursivo -artigo assinado. O comando explicita o objetivo discursivo no tocante à construção da argumentação e o convencimento do interlocutor acerca de determinado tema, nesse caso em específico o uso do smartphone em sala de aula. Assim, o comando da questão aciona a capacidade leitora dos estudantes com foco na ideia central defendida pelo autor do texto, ou seja, requer a identificação da tese em cada um dos textos, assim como a seleção de excertos que comprovem essa tese. Dessa forma, a questão mobiliza uma leitura comparativa para identificação dos diferentes posicionamentos nos dois textos lidos pelo grupo. Desse modo, a atividade parte de extrato mais amplo de análise do texto.

Na questão 02, por sua vez, observamos uma formulação mais diretiva a fim de buscar os argumentos apresentados pelos autores, abordando assim um conteúdo específico - tipos de argumentação. Há também uma relação com a regularidade do gênero em estudo, a saber, artigo assinado. Nessa questão, o comando, inicialmente, solicita uma identificação "Quais os argumentos utilizados pelos autores para demonstrar seus pontos de vistas? Comprove com passagens dos textos.”.

Embora as questões 01 e 02 remetam a uma certa regularidade de gênero, não se parte de uma análise das condições de produção e de circulação do gênero, ou seja, das interações sociais e discursivas que se dão por meio de um artigo assinado, mas de um olhar para a estrutura e materialidade textual do gênero. Não há indicações sobre os modos como a posição discursiva dos autores influencia no seu posicionamento (a favor ou contra; quem diz, de que lugar diz e porque diz). O foco está nas noções de tese e argumento, conteúdos clássicos de orientação epistemológica da semântica argumentativa.

As questões 03 e 04 , por seu turno, continuam a solicitar a noção de argumento, pois requerem que o estudante reflita sobre a função desses tipos de argumentos para construção de sentidos no texto (argumento de autoridade, pergunta retórica etc.). 
Já a questão 05 explicitamente trabalha com conteúdos orientados pela linguística textual, mais especificamente a coesão textual. Para tanto, solicita a identificação de elementos anafóricos no texto. A junção de metalinguagem como pronomes e referenciação, por exemplo, evidencia uma conciliação entre a gramática tradicional e estudos linguísticos. Nesse caso, o comando utilizado é identificar, como em: "Identifique as palavras que fazem referência a outras já citadas no texto e indique a que elas se referem".

Na questão 06, há uma continuidade no enfoque do estudo da linguística textual, neste caso, no uso de conectivos. O comando é iniciado com a apresentação de um conhecimento sistematizado sobre pontuação, como em: "Algumas palavras - os conectivos funcionam como ligação entre uma frase e outra, estabelecendo diferentes relações entre elas, como por exemplo, relação de oposição, demonstrada pelos conectivos mas, porém, todavia, contudo, no entanto etc.”. Essa exposição inicial é positiva, pois se distancia de uma postura normativista que exige o conhecimento enciclopédico de regras gramaticais. Além disso, a questão explora conectivos de oposição que são recorrentes na escola, ou seja, procura trabalhar aspectos linguísticos que circulam nas práticas letradas contemporâneas e não as regras de exceção como comumentemente se faz em um ensino gramatical tradicional.

A seguir, na questão 07, há uma mudança de tópico gramatical a ser abordado: de coesão textual, passa-se a focalizar o léxico, relacionando-o ao sentido do texto. De fato, é o primeiro momento em que o sentido do texto parece estar em primeiro plano nessa sequência de atividades. Quando a questão propõe o seguinte encaminhamento: "No texto de Tuma, retirado da Revista Carta Capital, há a expressão "engenhocas". A que ela se refere? Explique o porquê do autor ter utilizado essa expressão.", percebemos uma intenção de fazer com que os estudantes percebam que há uma valoração axiológica no uso do léxico engenhoca no texto, já que esse termo faz referência ao objeto de discurso do artigo - a saber, o smartphone. Tendo em vista que o articulista é contrário ao uso de smartphone em sala de aula, o referido termo carrega um tom depreciativo. Desse modo, essa questão é a que se mostra mais inovadora no sentido de possibilitar uma reflexão sobre o uso da língua em função dos objetivos discursivos dos interlocutores.

Na questão 08, tem-se a focalização de uma categorial gramatical, mais especificamente uma locução adjetiva que incide significativamente na construção dos sentidos do texto. Vejamos o enunciado da questão proposta: "No mesmo artigo, há entre parênteses uma adjetivação endereçada aos alunos. A que alunos especificamente essa locução adjetiva se refere? É depreciativo ou não? De que modo ela se relaciona com a posição defendida pelo autor ao longo do texto.”. Em resposta a essa questão, os estudantes deveriam identificar no texto a locução adjetiva "os mais cara de pau”. A observação dessa locução mostra-se extremamente produtiva para se discutir a orientação valorativa dessa forma de referenciar, no texto em estudo, os estudantes que usam o smartphone em sala de aula e como essa locução adjetiva remete ao ponto de vista do articulista.

Nessa questão, houve a intervenção da professora orientadora, pois inicialmente o enunciado da questão havia sido formulado da seguinte forma: "No mesmo artigo, há entre parênteses um adjetivo endereçado aos alunos. De que modo ela se relaciona com a posição defendida pelo autor ao longo do texto.”. Ou seja, a reescrita da questão no que se refere à explicitação do aspecto da valoração axiológica ${ }^{12}$ inscrita no texto e suas implicações na construção de sentidos foi um direcionamento da professora orientadora, haja vista que tal elemento não fora observado pelas licenciandas em sua formulação inicial. Na questão 07, por exemplo, onde a intervenção da professora orientadora não é tão incisiva, a valoração e suas implicações nos sentidos produzidos não estão explícitas no enunciado da questão. Tais intervenções ocorrem em todo o percurso da formação docente, sobretudo, nesse período de produção de material didático e apontam para um processo de coautoria dessas produções centradas na relação interlocutiva entre licenciando e professor orientador. Além disso, evidencia o processo de apropriação dos licenciandos desse modo de construir sua autoria docente no que tange à produção de materiais didáticos.

Na última questão (09), é retomado o trabalho pontual com conectivos, porém, nesse momento, é solicitada uma posição mais ativa dos estudantes uma vez que demanda a ação de reescrever, como se observa em: "O trecho reproduzido abaixo possui uma recorrência

\footnotetext{
${ }^{12} \mathrm{~A}$ noção de valoração axiológica está ligada ao conceito de horizonte social/axiológico elaborado pelo Círculo de Bakhtin. Configura, portanto, o conjunto de valorações (axiologias) que envolvem determinado enunciado. O fato de a palavra - entendida como signo ideológico - e o discurso terem suas raízes na interação social implica que eles sejam assinalados pelo horizonte axiológico/horizonte social de uma determinada época e de um determinado grupo social. Ou seja, os horizontes sociais/axiológicos, frutos das ideologias de um dado grupo social de uma dada época, materializam-se na linguagem. (SILVEIRA; ROHLING; RODRIGUES, 2012, p.61).
} 
do conectivo "com". Reescreva o trecho, de forma a não alterar o sentido, retirando um ou mais desses conectivos.". A solicitação para reescrever, criar, comparar, aponta para o fato de que:

[...] no lugar da classificação e da identificação, ganha espaço a reflexão. A partir de atividades linguísticas (leitura/escuta e produção oral e escrita) e epilinguísticas (comparar, transformar, reinventar, enfim refletir sobre construções e estratégias linguísticas e discursivas), que familiarizam com o aluno os fatos da língua, este pode chegar às atividades metalinguísticas, quando a reflexão é voltada para a descrição, categorização e sistematização dos conhecimentos, utilizando-se nomenclaturas. (MENDONÇA, 2006, p. 208).

De modo geral, nessa atividade, é possível dizer que há uma imbricação entre a tendência conciliadora e tendência inovadora, tendo em vista que há nas questões elementos da tradição, como no comando 'identifique', no uso de nomenclatura da gramática tradicional e na explicitação de conhecimentos sistematizados sobre a língua. Por outro lado, em outras questões há um movimento de fazer que o aluno reescreva, justifique/argumente sua resposta, compare usos linguísticos a fim de fazê-lo refletir sobre os fatos da língua numa perspectiva epilinguística. Observamos questões que adotam denominações (referenciação, coesão textual e coerência) para o estudo da língua inspiradas nas contribuições da linguística e se caracterizam pela não sistematização de temas (REINALDO; BEZERRA, 2013, p. 58). Assim, há questões em que não se abordam os fenômenos linguísticos de modo explícito, mas demandam a compreensão do conteúdo específico trabalhado e a capacidade de depreender regras a partir do estudo de tal conteúdo.

Por fim, vale destacar que, nos dados analisados, os elementos relacionados às regularidades discursivas, textuais e linguísticas dos gêneros discursivos foram pouco abordados nas questões propostas. O gênero discursivo possui uma dimensão linguageira, concretizada no estilo, que é um dos elementos constitutivo do gênero. Segundo Bakhtin (2003, p. 262), o estilo é a própria “[...] seleção dos recursos léxicos, fraseológicos e gramaticais da língua [...]”. Trata-se então da relação dos enunciados de determinado gênero com os usos sociais da língua. Desse modo, analisar as regularidades de gênero (dimensão social e verbal dos enunciados), sobretudo, o estilo é também estudar a língua em uso. A partir da análise das atividades desenvolvidas, é possível dizer que não houve uma assimilação mais acentuada, por parte dos licenciandos, da concepção de que o estudo do texto, a partir de suas regularidades de gênero, implica também a análise da materialidade linguística, mais especificamente os fatos da língua próprios de determinados gêneros discursivos e que tal reflexão integra o trabalho na concepção de AL.

\section{CONSIDERAÇÕES FINAIS}

Na análise empreendida, constatamos que, na formação inicial, o processo de descentralização do papel da gramática no ensino de língua ainda está em construção. Trabalhar os aspectos gramaticais do texto, no texto e pelo texto é um desafio que exige que substituamos os quadros teóricos que serviram à tradição gramatical por práticas que envolvam os diferentes usos da língua.

Observamos, nas atividades analisadas, uma concepção de prática de AL voltada para a linguagem em uso e para uma perspectiva mais reflexiva da língua, mas também vimos emergir o discurso da tradição em ensino de LP, que remete aos saberes escolares tradicionais de modo saliente (na atividade 1, por exemplo). Assim, a análise apresentada evidencia não só um movimento de prospecção, como também de retroação, visto que é possível constatar um processo de assimilação das novas demandas de ensino língua na escola, mas, ao mesmo tempo, identifica-se a reprodução de modelos e práticas gramaticais tradicionais.

Tal constatação reafirma a responsabilidade da instância formadora desses futuros professores para que possam superar as práticas gramaticais descontextualizadas e pouco significativas para as demandas de letramento dos sujeitos envolvidos e apontar caminhos para um trabalho com a AL, de modo produtivo e articulado às demais práticas de linguagem (escuta, leitura, produção de texto oral e escrito). 


\section{REFERÊNCIAS}

ALLAN, Luciana. A proibição do celular nas escolas faz sentido. Porvir, 30 jul. 2013. Disponível em: $<$ http://porvir.org/porpensar/proibicao-celular-nas-escolas-faz-sentido/20130730 > . Acesso em: 9 jul. 2015.

BAKHTIN, Mikhail M.; VOLOCHÍNOV, V. N. Marxismo e filosofia da linguagem: problemas fundamentais do método sociológico na ciência da linguagem. Tradução do francês por Michel Lahud e Yara F. Vieira. 11. ed. São Paulo: Hucitec, 2004. [1929].

BAKHTIN, Mikhail M. Estética da criação verbal. Tradução do russo por Paulo Bezerra. 4. ed. São Paulo: Martins Fontes, 2003. [1979].

BAKHTIN, Mikhail M.. Questões de estilística no ensino de língua. Tradução e posfácio de Sheila Grillo e Ekaterina V. Américo. São Paulo: Editora 34, 2013.

BRASIL. Secretaria de Educação Fundamental. Parâmetros Curriculares Nacionais: terceiro e quarto ciclos do ensino fundamental: introdução aos parâmetros curriculares nacionais. Brasília: MEC/SEF, 1998.

FRANCHI, Carlos. Criatividade e gramática. São Paulo: SE/Cenp, 1991.

GERALDI, J.W.. Concepções de linguagem e o ensino de Português. In: GERALDI, J.W. (Org.) O texto na sala de aula. São Paulo: Ática, 1984. p. 39-45.

Portos de passagem. 4. ed. São Paulo: Martins Fontes, 1997.

. Linguagem e ensino. Exercícios de militância e divulgação. Campinas: Mercado de Letras, 2002.

HEATH, S. B. Protean shapes in literacy events: Ever-shifting oral and literate traditions. In: TANNEN, D. (Ed.). Spoken and written language: Exploring orality and literacy. Ablex: Norwood, N.J,1982. p. 91-117.

MENDONÇA, M. Análise Linguística no Ensino Médio: um novo olhar, um outro objeto. In: BUNZEN, Clécio; MENDONÇA, Márcia (Org.). Português no ensino médio e formação do professor. São Paulo. Parábola Editorial, 2006. p. 199-226.

MORSON, Gary Saul; EMERSON, Caryl. Bakhtin: criação de uma prosaística. Tradução de Antônio de Pádua Danesi. São Paulo: Editora da Universidade de São Paulo, 2008.

REINALDO, M. A.; BEZERRA, M. A. Análise linguística: afinal a que se refere? São Paulo: Cortez, 2013.

RIBEIRO, Nilsa Brito. O discurso da relação entre teoria e prática na formação do professor de Português. SIGNUM: Estud. Ling., Londrina, n. 16/2, p. 271-292, dez. 2013.

RODRIGUES, Nara Caetano. O discurso do professor de língua portuguesa no processo de reestruturação curricular: uma construção dialógica. 2009. 314 f. Tese (Doutorado) - Programa de Pós-Graduação em Linguística, Universidade Federal de Santa Catarina, Florianópolis, 2009.

RODRIGUES, Nara Caetano. Análise linguística na escola: reflexões sobre um processo de elaboração didática. In: ROMAN, E. C.; FRAGA, L.; BORGES, M. I. (Org.). Questões gramaticais: algumas possibilidades. Blumenau: Muitas Vozes, 2014. p. 77-89.

SILVEIRA, Ana Paula K. da; ROHLING, Nívea; RODRIGUES, Rosângela Hammes. A Análise dialógica dos gêneros do discurso e os estudos de letramento: glossário para leitores iniciantes. Florianópolis: DIOESC, 2012 
SOARES, Magda. Português na escola - História de uma disciplina curricular. In: BAGNO, Marcos (Org.). Lingüística da norma. São Paulo: Edições Loyola, 2002. p. 155-177.

TARDIF, Maurice. Saberes docentes e formação profissional. Petrópolis: Vozes, 2002.

TRAVAGLIA, L.C. Gramática e interação: uma proposta para o ensino de gramática no $1^{\circ}$ e 2º graus. 6. ed. São Paulo: Cortez, 2001.

TUMA, Rogério. Na sala de aula, não. Carta Capital. Disponível em: <http://www.cartacapital.com.br/revista/772/na-sala-de-aulanao-3798.html>. Acesso em: 09 jul. 201.

Recebido em 12 / 05 / 2015. Aprovado em 12 / 09 / 2015. 